\title{
УГОЛОВНАЯ ОТВЕТСТВЕННОСТЬ
}

\section{ЗА УКЛОНЕНИЕ ОТ УПЛАТЫ НАЛОГОВ}

И (ИЛИ) СБОРОВ В РОССИЙСКОЙ ФЕДЕРАЦИИ

И ЗАРУБЕЖНЫХ СТРАНАХ

\section{НА ПРИМЕРЕ ОТВЕТСТВЕННОСТИ ОРГАНИЗАЦИЙ}

\begin{abstract}
Аннотация. В данной статье рассмотрены отдельные вопросы уголовной ответственности за уклонение от уплаты налогов и (или) в Российской Федерации и зарубежных станах. На основе метода сравнительного исследования приведены основные мировые показатели не поступления средств в бюджеты государств различных уровней, вследствие уклонения от уплаты налогов. Указан зарубежный опыт как один из источников совершенствования национального законодательства, в частности автор сопоставляет опыт уголовной ответственности за уклонение от уплаты налогов в США и РФ. В статье даётся обобщённая характеристика отдельных способов борьбы с налоговыми преступлениями в государствах различных типов. С учётом исследования автором предлагаются отдельные меры развития уголовной ответственности за уклонение от уплаты налогов и (или) сборов с организации в РФ, которые могут быть использованы как в теоретическом аспекте, так и для практических целей законодательного совершенствования и правоприменения.
\end{abstract}

Ключевые слова: уголовная ответственность, налоговые преступления, финансовые преступления, зарубежное законодательство, налоговое правонарушение, налогооблажение, уголовно-правовые нормы, зарубежный опыт, налоговое законодательство, налоговое уголовное право.

Review. The present article is devoted to particular issues of criminal liability for avoidance of paying taxes and/or levies in the Russian Federation and foreign states. By using the method of peer reviews, the author of the article provides the key figures of different countries not receiving budget revenues as a result of evasion of taxes. The author focuses on foreign experience as one of the sources of information about how to improve national legislation. In particular, the author compares the experience of imposing criminal liability for evasion of taxes in the USA and Russian Federation. The article contains a general description of particular methods of preventing tax crime in different countries. Based on the research, the author offers concrete measures to develop the sphere of criminal liability for evasion of taxes and/or levies by organizations in the Russian Federation. These measures can serve both as a theoretical concept and practical recommendations on how to improve the effective legislation.

Keywords: criminal liability, tax crime, financial crime, foreign legislation, violation of tax law, taxation, standards of criminal law, foreign experience, tax legislation, tax criminal law. 
Тема: Налоговые преступления: особенности уголовно-правовой характеристики

Таблица 1. Рейтинг мировых лидеров по потерям налоговых поступлений в результате налоговых правонарушений и преступлений (2011 год)

\begin{tabular}{|l|l|l|}
\hline № & Страна & Совокупные годовые потери (млрд. долл.) \\
\hline 1 & США & 337,3 \\
\hline 2 & Бразилия & 280,1 \\
\hline 3 & Италия & 238,7 \\
\hline 4 & Россия & 221 \\
\hline 5 & Германия & 215 \\
\hline 6 & Франция & 171,3 \\
\hline 7 & Япония & 171,1 \\
\hline 8 & Китай & 134,4 \\
\hline 9 & Великобритания & 109,2 \\
\hline 10 & Испания & 107,4 \\
\hline
\end{tabular}

Источник: материаль сайта http://www.taxjustice.net

K ак известно, за счет налогов, взимаемых с налогоплательщиков, формируются основные для государства ресурсы, от которых полностью зависит система жизнеобеспечения всего общества. Уклонение от налогов, в данном контексте - одно из опаснейших преступлений, направленных против стабильности общественных отношений.

Среди наиболее существенных последствий уклонения от уплаты налогов можно выделить:

- сокращение налоговых поступлений в бюджет;

- искажение ценовых соотношений и нарушение рыночной конкуренции;

- $\quad$ нарушение принципа социальной справедливости.

Следовательно, уклонение от уплаты налогов не просто противоречит действующим нормам права, но и нарушает интересы граждан, материальное обеспечение которых должно полностью или частично осуществляться обществом и государством.

В связи с этим, особую значимость приобретают меры, предпринимаемые государством для охраны налогового законо- дательства. Также отметим, что уклонение от уплаты налогов, как специфический вид уголовно наказуемого деяния представляет собою интернациональное явление, которое развивалось вместе с налогообложением, исторически приобретая в разных странах форму устойчивой закономерности ${ }^{1}$.

Масштабы, данного явления, поистине огромны, и убытки государств, здесь, исчисляются в миллиардах долларов. Чтобы проиллюстрировать данное положение цифрами, отметим, что организация TJN в конце 2011 г. составила своеобразный рейтинг стран мировых лидеров по потерям налоговых поступлений вследствие уклонения от исполнения обязанностей налогоплательщиков. Россия удостоилась 4 строчки данного рейтинга (см. таблицу № 1).

Гигантские потери государства от налоговых преступлений обуславливают необхо-

\footnotetext{
${ }^{1}$ Майбуров И.А. Массовый оппортунизм налогоплательщиков как следствие отсутствия в нашем обществе налоговой морали / И. А. Майбуров. [Электронный реcypc] // URL.: Режим доступа: [http://www.cnfp.ru/publish/ journal/2012/2012-09.php].
} 
димость активной борьбы по защите налоговой системы от преступных посягательств, в том числе (в случае РФ) и за счет учета опыта и заимствования отдельных норм, положений и институтов из законодательств других государств. Указанное положение, формирует актуальность настоящей работы.

Также отметим, тот факт, что Россия лишь недавно приступила к формированию рыночных структур и отношений, при этом она не успела еще накопить значительный опыт борьбы с подобными специфическими преступлениями, присущими именно современному рыночному хозяйству. Современная система ответственности за налоговые преступления (если не учитывать морально устаревший дореволюционный опыт, и построенный на совершенно других принципах опыт советский) сформирована лишь в последние два десятилетия, что по мировым “меркам” достаточно мало. Определенные проблемы, также связаны и с самой сущностью налоговых преступлений.

В частности, в литературе отмечается, что налоговые преступления являются частью преступлений финансовых, которые, год от года становятся все более изощренными, в то время как преступники аккумулируют значительные суммы денег (совершая преступления, связанные с незаконным оборотом наркотиков, инвестиционным мошенничеством, вымогательством, коррупцией, хищением имущества, уклонением от уплаты налогов и налоговым мошенничеством).

Сам характер финансового преступления означает, что одно деяние может нарушать разные законы. Различные ведомства могут быть вовлечены на разных стадиях борьбы с финансовыми преступлениями, включая предупреждение, выявление, расследование и уголовное преследование преступлений, а также возвращение средств, полученных преступным путем.
Налоговые преступления по своей природе зачастую связаны с иными финансовыми преступлениями, поскольку преступники не декларируют в налоговых целях свои доходы, полученные от незаконной деятельности. И наоборот - преступники могут завышать размеры своих доходов в попытке отмыть доходы, полученные преступным путем.

На настоящий момент, в России, налоговым преступлением в соответствии со ст. 198 и 199 Уголовного кодекса РФ1ㅛ признается уклонение налогоплательщиков в разных формах от уплаты налогов и сборов. За нарушения в налоговом законодательстве и уклонения от уплаты налогов и сборов законодательством предусмотрена уголовная ответственность граждан и должностных лиц. Например, лица, осуществляющие в организациях административно-распорядительные функции, могут нести административную ответственность и в то же время - быть оштрафованы за налоговые правонарушения в случае, когда они выступали в налоговых отношениях от своего имени в качестве налогоплательщика ${ }^{2}$.

Физическое лицо может быть привлечено к налоговой ответственности с шестнадцатилетнего возраста. Предусмотренная НК ответственность за деяние, совершенное физическим лицом, наступает, если это деяние не содержит признаков состава преступления, предусмотренного уголовным законодательством РФ.

Привлечение должностных лиц организации к ответственности за совершение

\footnotetext{
${ }^{1}$ Уголовный кодекс Российской Федерации. Федеральный закон от 13.06.1996 № 63-Ф3 (ред. от 01.09.2013) [Текст] // Собрание законодательства РФ.—-17.06.1996.— № 25.

${ }^{2}$ Козырев, А.А. Некоторые вопросы ответственности за нарушение законодательства о налогах и сборах [Текст] / А. А. Козырев // Государство и право._-2010.№ 4. C. 25 .
} 
налогового правонарушения не освобождает их же при наличии соответствующих оснований от административной, уголовной или иной ответственности, предусмотренной законами РФ.

В соответствии с общеправовым принципом, закрепленным в ст. 50 Конституции Российской Федерации ${ }^{1}$, ст. 6 УК РФ, ст. 4.1 КоАП РФ²и ст. 108 НК РФ ${ }^{3}$, привлечение физического лица одновременно к уголовной, административной и налоговой ответственности за одно и то же правонарушение недопустимо.

Это же отметил и Пленум Высшего Арбитражного Суда Российской Федерации в П. 34 Постановления от 28 февраля 2001 г. № 5 “О некоторых вопросах применения части первой Налогового кодекса Российской Федерации". ${ }^{4}$

Специалисты, отмечают, что действующее законодательное регулирование ответственности за нарушения в сфере налогообложения характеризуется нечеткостью и противоречивостью. По значительному кругу вопросов не достигнуто господствующего мнения и в правоприменительной практике и юридической литературе [6;9].

\footnotetext{
${ }^{1}$ Конституция Российской Федерации. Принята Всенародным голосованием 12 декабря 1993 года (ред. от 30.12.2008) [Текст] // Российская газета.25.12.1993. - № 237.

${ }^{2}$ Кодекс об административных правонарушениях. Федеральный закон от 30.12.2001 № 195-ФЗ (ред. от 01.10.2013) [Текст] // Собрание законодательства РФ.— 07.01.2002.—№ 1 (ч. 1).

${ }^{3}$ Налоговый кодекс Российской Федерации. Часть первая. Федеральный закон от 31.07.1998 № 146-Ф3 (ред. от 01.10.2013) [Текст] // Собрание законодательства РФ.— № 31.- 03.08.1998.

${ }^{4}$ О некоторых вопросах применения части первой Налогового кодекса Российской Федерации. Постановление Пленума Высшего Арбитражного Суда Российской Федерации от 28 февраля 2001 г. № 5 [Электронный ресурс] // СПС Консультант Плюс.
}

В частности, споры вызывает сама система ответственности за нарушения законодательства о налогах и сборах, нет единства в мнении о конструкции этих преступлений, имеются сложности в выявлении элементов и признаков состава налогового преступления и т.д.

В данной ситуации, обращение к опыту зарубежных государств, на наш взгляд, является очевидным и весьма полезным.

Наш обзор уголовной ответственности за уклонение от уплаты налогов и (или) сборов зарубежных странах мы начнем с констатации того факта, что определяя степень уголовно-правового воздействия и санкции за совершение налоговых преступлений, законодатель каждой из стран исходит из конкретных экономических, политических, социальных, правовых, географических и иных особенностей своей страны, которые обусловлены ее историей, типом государственного и общественного устройства, традициями, видом правовой системы, что в совокупности и определяет степень опасности налоговых преступлений и правонарушений для общества и государства.

Особенностью уголовно-правовых норм об умышленном уклонении от уплаты налогов является то, что они могут находиться не только в Уголовном кодексе, но и в нормативных актах налогового законодательства.

Так, во многих странах Европы эта комплексная область права, включающая в себя совокупность норм собственно уголовного права и налогового законодательства, которые используются в качестве бланкетного нормативного материала, в совокупности именуется как “налоговое уголовное право”.

Само понятие уклонения от уплаты налогов также по-разному формулируется в теории и практике разных государств. В одних странах понятие уклонения определяется 


\section{Налоги и налогообложение - №11(113)• 2013}

налоговым, в других — уголовных законодательством. При этом в мировой практике, существует несколько способов борьбы с уклонением от уплаты налогов ${ }^{1}$ :

- совершенствование нормативно-правовой базы, дающее возможность закрыть вполне законные пути, используемые для уклонения от уплаты налогов;

- ужесточение санкций против нарушителей налогового законодательства;

- формирование современного комплекса организационных и правовых мер по предупреждению, контролю и пресечению ухода от налогообложения.

Судебная и следственная практика развитых стран Запада², также свидетельствует о том, что преступления в финансовой сфере, в большинстве своем, являются “консенсусными", т.е. совершаются по предварительному сговору сторон. Именно поэтому отмечается сложность документирования и формирования доказательной базы подобных преступлений, поскольку основные участники противоправных действий глубоко законспирированы, а их действия, как правило, тщательно спланированы и хорошо организованы

Интересен тот факт, что за рубежом налоговые преступления в основном включают в так называемые "корпоративные преступления”, - в иной транскрипции - относят к преступности корпораций ${ }^{3}$ (куда входят преступления, как самих юридических лиц - корпораций, так и представителей

\footnotetext{
1 Чуриков, А.А. Ответственность за налоговые преступления: Учет зарубежного опыта в отечественной практике [Текст] /А. А. Чуриков. // "Черные дыры" в Российском законодательстве.-2011.-№ 4.-С. 268.

${ }^{2}$ Там же.- С. 270.

${ }^{3}$ Смирнов, А. В. Финансовые санкции за нарушение налогового законодательства: отечественный и зарубежный опыт [Текст] / А. В. Смирнов.- М.: Приор Издат, 2008.
}

администрации корпорации). Таким образом, одной из характерных особенностей уголовного права многих зарубежных государств является существование института уголовной ответственности корпораций (юридических лиц). Первоначально, этот институт был характерен для стран с англосаксонской системой права, но впоследствии его восприняли и многие страны континентальной Европы.

В США ответственность за налоговые преступления, связанная с деятельностью юридических лиц, имеет ряд особенностей по сравнению с ответственностью физических лиц. Очень часто в делах по уголовнонаказуемому уклонению от уплаты налогов, где должностное лицо предприятия выступает в роли обвиняемого, в ходе рассмотрения дела изучается как налоговый статус корпорации, так и индивидуальный статус обвиняемого должностного лица в целях установления, в чьих интересах действовало лицо. Обычно при уклонении корпорации от уплаты налогов доход корпорации скрывается от налогообложения в личных интересах того, у кого есть возможность осуществлять подобные операции. Однако уголовно-правовые санкции могут быть применены против должностного лица корпорации и независимо от того, было ли оно лично заинтересовано в данном правонарушении. Если юридическое лицо совершает преступление, то должностные лица и директора компании считаются виновными в преступном заговоре 4 .

На наш взгляд заимствование отдельных норм уголовного права США представляет интерес в целях необходимости криминализации и разграничения уклонения от уплаты

\footnotetext{
4 Чуриков, А.А. Ответственность за налоговые преступления: Учет зарубежного опыта в отечественной практике ... С. 269.
} 
налогов в интересах предприятия и в интересах отдельных лиц, т.е. два объекта посягательства - экономические интересы государства в области формирования государственного бюджета и интересы службы в коммерческих и иных организациях.

Большой практический интерес, в контексте нашей темы, также, представляют способы распределения полномочий по борьбе с налоговыми преступлениями в различных странах. В отчете Организации Экономического сотрудничества и Развития (ОСЭР) за 2012 год, выделяются следующие модели:

Модель 1: налоговая администрация отвечает за руководство и проведение расследований. Данная модель применяется в Австралии, Канаде, Германии, Греции, Индии, Ирландии, Корее, Новой Зеландии, Южной Африке, Швейцарии, Великобритании и США.

Модель 2: налоговая администрация отвечает за проведение расследований под руководством генерального прокурора. Данная модель применяется в Австрии, Чили, Голландии, Португалии, Швеции, Испании. В настоящее время в Испании расследование налоговых преступлений проводится под руководством допрашивающего судьи.

Модель 3: специализированный налоговый орган под надзором Министерства финансов, но не входящий в налоговую администрацию, отвечает за проведение расследований. Данная модель применяется в Греции, Исландии и Турции.

Модель 4: полиция или прокуратура отвечают за проведение расследований. Данная модель применяется в Бельгии, Чехии, Дании, Финляндии, Франции, Японии, Люксембурге, Мексике, Норвегии, Словакии и Словении.

В России, на наш взгляд, применятся отдельные элементы из этих моделей в со- вокупности, что с одной стороны позитивно - так как дает обширные возможности по борьбе с преступлениями, а с другой стороны - определенным образом "распыляет" ответственность.

В целом, хотелось бы отметить, что уклонение от налогов — это неизбежный процесс, характерный для всех стран мира. Однако существует реальная возможность уменьшения масштабов данного явления. Например, в качестве мер, которые необходимо предпринимать в рамках международного сотрудничества по борьбе с уклонением от уплаты налогов, выделяют:

- информационный обмен между странами;

- обязанность идентификации;

- $\quad$ свободный доступ сотрудников органов внутренних дел для выезда или въезда в зарубежные страны по делам данной категории.

Для эффективной борьбы с уклонением от уплаты налогов с организаций, а также при становлении правоохранительной работы в сфере налогообложения, в рамках отдельного государства — России, стоит дополнительно учесть некоторые основные положительные моменты, характерные для системы сбора налогов в зарубежных странах, влияющих на борьбу с налоговой преступностью. В частности, в число указанных мер можно отнести:

- возможности рецепции принципиально нового подхода к замене уголовной ответственности на административную при совершении неумышленного уклонения от уплаты налогов (не связанного с мошенническими действиями). Ярким примером, здесь, служит Германия, где в ситуациях, когда обвинение сталкивается со сложностями при доказывании умысла, направленного на уклонение от уплаты налогов, действуют альтернативные нормы об административной 
ответственности, предусматривающие крупные штрафы за формальные нарушения налогового законодательства (в том числе неосторожные);

- интересна модель перехода от жестких к лояльным методам налогового контроля, т. е. к методам, направленным на помощь юридическим лицам в организации правильного ведения налоговой отчетности;

- на наш взгляд, необходимо позаимствовать опыт ряда экономически развитых стран мира по возможности привлечения к уголовной ответственности юридических лиц за налоговые преступления, ведь уклонение от уплаты налогов осуществляется зачастую не только в личных интересах руководителя фирмы, но и в интересах предприятия, где присутствуют интересы всех учредителей.

В целом, зарубежный опыт, привлечения к уголовной ответственности за уклонение от уплаты налогов и (или) сборов с организаций весьма разнообразен и интересен, а отдельные, наиболее удачные модели борьбы с налоговыми преступлениями, достойны пристального изучения, и внедрения в рамках отечественного права.

\section{Библиография}

1. Конституция Российской Федерации. Принята Всенародным голосованием 12 декабря 1993 года (ред. от 30.12.2008) [Текст] // Российская газета.-25.12.1993.-№ 237.

2. Кодекс об административных правонарушениях. Федеральный закон от 30.12.2001 № 195-Ф3 (ред. от 01.10.2013) [Текст] // Собрание законодательства РФ.-07.01.2002.—№ 1 (ч. 1).- Ст. 1.

3. Налоговый кодекс Российской Федерации. Часть первая. Федеральный закон от 31.07.1998 № 146-Ф3 (ред. от 01.10.2013) [Текст] // Собрание законодательства РФ.—№ 31.-03.08.1998.— С т. 3824

4. Уголовный кодекс Российской Федерации. Федеральный закон от 13.06.1996 № 63-Ф3 (ред. от 01.09.2013) [Текст] // Собрание законодательства РФ.—17.06.1996.—№ 25.— Ст. 2954.

5. О некоторых вопросах применения части первой Налогового кодекса Российской Федерации. Постановление Пленума Высшего Арбитражного Суда Российской Федерации от 28 февраля
2001 г. № 5 [Электронный ресурс] // СПС Консультант Плюс

6. Глушко Д. Е. К вопросу о налоговых правонарушениях и преступлениях: основные аспекты [Текст] / Д. Е. Глушко // Налоги.- 2007.- № 2

7. Козырев, А.А. Некоторые вопросы ответственности за нарушение законодательства о налогах и сборах [Текст] / А.А. Козырев// Государство $\neg$ и право.- 2010.—№ 4.

8. Майбуров И. А. Массовый оппортунизм налогоплательщиков как следствие отсутствия в нашем обществе налоговой морали /И.А. Майбуров. [Электронный ресурс] // URL.: Режим доступа: [http://www.cnfp.ru/publish/ journal/2012/2012-09.php]

9. Симин В.И. Уклонение от уплаты налогов: причины, способы и средства пресечения [Текст] / В. И. Симин // Финансовое право.-2009.-—№ 1

10. Смирнов, А. В. Финансовые санкции за нарушение налогового законодательства: отечественный и зарубежный опыт [Текст] / А. В. Смирнов.- М.: Приор Издат, 2008. 
11. Чуриков, А.А. Ответственность заналоговые преступления: Учет зарубежного опыта в отечественной практике [Текст] /А. А. Чуриков. // “Черные дыры" в Российском законодательстве.—2011.—№ 4.— С. 268.
12. Эффективное межведомственное сотрудничество в области борьбы с налоговыми и другими финансовыми преступлениями [Электронный ресурс] // URL.: http://www.oecd.org/ctp/crime/ Final_Russian_Domestic_Cooperation.pd

\section{References (transliterated)}

1. Konstitutsiya Rossiiskoi Federatsii. Prinyata Vsenarodnym golosovaniem 12 dekabrya 1993 goda (red. ot 30.12.2008) [Tekst] // Rossiiskaya gazeta.—25.12.1993.—№ 237.

2. Kodeks ob administrativnykh pravonarusheniyakh. Federal'nyi zakon ot 30.12.2001 № 195-FZ (red. ot 01.10.2013) [Tekst] // Sobranie zakonodatel'stva RF.07.01.2002.—№ 1 (ch. 1).— St. 1.

3. Nalogovyi kodeks Rossiiskoi Federatsii. Chast" pervaya. Federal'nyi zakon ot 31.07.1998 № 146-FZ (red. ot 01.10.2013) [Tekst] // Sobranie zakonodatel'stva RF.№ 31.-03.08.1998. - St. 3824

4. Ugolovnyi kodeks Rossiiskoi Federatsii. Federal'nyi zakon ot 13.06.1996 № 63FZ (red. ot 01.09.2013) [Tekst] // Sobranie zakonodatel'stva RF.—17.06.1996.№ 25.- St. 2954 .

5. O nekotorykh voprosakh primeneniya chasti pervoi Nalogovogo kodeksa Rossiiskoi Federatsii. Postanovlenie Plenuma Vysshego Arbitrazhnogo Suda Rossiiskoi Federatsii ot 28 fevralya 2001 g. № 5 [Elektronnyi resurs] // SPS Konsul'tant Plyus

6. Glushko D. E. K voprosu o nalogovykh pravonarusheniyakh i prestupleniyakh: osnovnye aspekty [Tekst] / D. E. Glushko // Nalogi.—2007.— № 2
7. Kozyrev, A. A. Nekotorye voprosy otvetstvennosti za narushenie zakonodatel'stva o nalogakh i sborakh [Tekst] / A. A. Kozyrev// Gosudarstvo $\neg$ i pravo.- 2010.—№ 4.

8. Maiburov I. A. Massovyi opportunizm nalogoplatel'shchikov kak sledstvie otsutstviya $\mathrm{v}$ nashem obshchestve nalogovoi morali /I.A. Maiburov. [Elektronnyi resurs] // URL.: Rezhim dostupa: [http://www.cnfp.ru/publish/ journal/2012/2012-09.php]

9. Simin V.I. Uklonenie ot uplaty nalogov: prichiny, sposoby i sredstva presecheniya [Tekst] / V.I. Simin // Finansovoe pravo._-2009.—№ 1

10. Smirnov, A. V. Finansovye sanktsii za narushenie nalogovogo zakonodatel'stva: otechestvennyi i zarubezhnyi opyt [Tekst] / A. V. Smirnov. - M.: Prior Izdat, 2008.

11. Churikov, A. A. Otvetstvennost" zanalogovye prestupleniya: Uchet zarubezhnogo opyta $\mathrm{v}$ otechestvennoi praktike [Tekst] /A. A. Churikov. // "Chernye dyry" v Rossiiskom zakonodatel'stve.—2011.—№ 4.— S. 268.

12. Effektivnoe mezhvedomstvennoe sotrudnichestvo v oblasti bor'by s nalogovymi i drugimi finansovymi prestupleniyami [Elektronnyi resurs] // URL.: http://www.oecd.org/ctp/crime/ Final_Russian_Domestic_Cooperation.pd 